\title{
O show matemática do milhão: divulgando e promovendo conhecimento
}

\section{The millionaire's math show: spreading and promoting knowledge}

DOI: $10.46814 / \operatorname{lajdv3n4-041}$

Recebimento dos originais: 01/05/2021

Aceitação para publicação: 31/06/2021

\section{Isabella Basílio Josaphá}

Mestre em Matemática

Instituição de atuação atual: Instituto Federal do Norte de Minas Gerais

Endereço completo: Travessa Américo Cury Carneiro, número 31, apartamento 201, Centro, 36520-

000, Visconde do Rio Branco, Minas Gerais, Brasil.

E-mail: isabella.josaphaa@gmail.com

\section{Gabriela França Oliveira}

Mestre em Estatística Aplicada e Biometria

Instituição de atuação atual: Universidade Federal de Viçosa

Endereço completo: Departamento de Estatística, Universidade Federal de Viçosa, Av. Peter Henry Rolfs, s/n, Campus Universitário, 36570-900, Viçosa, Minas Gerais, Brasil.

E-mail: gabriela.franca@ufv.br

\section{RESUMO}

Esse artigo trata da apresentação de um jogo intitulado "Show Matemática do Milhão", um jogo de perguntas que segue o formato do jogo televisivo "Show do Milhão" apresentado pela emissora de televisão SBT. O intuito do jogo foi despertar o interesse dos alunos por conteúdos matemáticos, visto que o jogo trata de diversos conteúdos de diversos níveis. O aluno acertando sente-se motivado a continuar os estudos e errado sente-se motivado a buscar o conhecimento para que o erro não se repita. Além de despertar o interesse dos alunos, o jogo também é interessante para professores que podem substituir uma avaliação formal de perguntar e respostas por essa avaliação mais dinâmica e divertida.

Palavras-Chave: Jogo, Recursos didáticos, Ensino de Matemática, Computador.

\begin{abstract}
This paper is about the presentation of a game called "Show Math do Milhão", a quiz game that follows the format of the TV game "Show do Milhão", presented by SBT television network. The purpose of the game was to awaken the students' interest for mathematical contents, since the game deals with several contents at different levels. When the student gets it right, he/she feels motivated to continue studying, and when he/she gets it wrong, he/she feels motivated to seek knowledge so that the mistake will not be repeated. Besides arousing the students' interest, the game is also interesting for teachers, who can replace a formal evaluation of questions and answers by this more dynamic and fun evaluation.
\end{abstract}

Keywords: Game, Didactic Resources, Mathematics Teaching, Computer. 


\section{INTRODUÇÃO}

Este texto apresenta um jogo elaborado por um grupo de alunas de Licenciatura em Matemática que teve como objetivo principal a divulgação e promoção do curso de Matemática junto a alunos do ensino médio no evento “UFV decisão de futuro". Segundo Carvalho (2005), os jogos podem se tornar ferramentas instrucionais eficientes, pois eles divertem e motivam, facilitando assim o aprendizado, pois aumenta a capacidade de retenção do que foi ensinado. A Matemática é vista muitas vezes como algo difícil, inalcançável, e muitos consideram que aprender Matemática é algo que não faz parte de sua realidade. Os jogos e desafios matemáticos são recursos que podem desmistificar essa visão sobre a disciplina, pois estimulam e incentivam os estudos já que, quando os alunos se sentem desafiados, buscam compreender os assuntos envolvidos no jogo para que possam ter êxito no mesmo. Por isso, para chamar a atenção dos alunos e professores do ensino médio, o grupo de licenciandas elaborou e confeccionou o jogo intitulado "Show Matemática do Milhão", em analogia ao conhecido "Show do Milhão", programa de perguntas e respostas exibido por uma emissora de televisão aberta que alcançou grande sucesso de audiência no período em que esteve no ar, entre $\underline{1999}$ e $\underline{2003}$. Um dos aspectos que se destacaram na sua aplicação é o empenho dos alunos para responder as questões. Foi possível verificar muitas potencialidades dos participantes para a área de matemática e, consequentemente, na continuidade dos estudos de graduação. Os professores também tiveram muito interesse pelo jogo, como um recurso didático para suas aulas.

\section{METODOLOGIA}

O grupo de licenciandas iniciou a confecção do jogo por meio da pesquisa de perguntas envolvendo conteúdos matemáticos e respostas que seriam fornecidas como alternativa aos participantes desafiados, sendo que apenas uma dentre quatro estaria correta. Buscando apresentar algo que se destacasse, já que o evento possuía outras exposições, o grupo se empenhou na elaboração do jogo a fim de torna-lo mais envolvente e atrativo. Prepararam uma apresentação em um telão com uma música de fundo que caracterizava o jogo original e arrecadaram prêmios que seriam distribuídos aos participantes, de acordo com o nível que atingissem ao participar do desafio. Foram elaboradas trinta apresentações diferentes, e em sequência, contendo cada uma dessas apresentações, quatro perguntas em três níveis de dificuldades (uma fácil, duas médias e uma difícil). O jogo foi apresentado em computador e exibido utilizando-se um projetor multimídia. Vale destacar que ele é interativo, de fácil manipulação e pode ser adequado aos conteúdos trabalhados por professores, do ensino básico ao ensino superior, podendo, portanto ser utilizado nas próprias aulas junto com alunos. 


\section{DESENVOLVIMENTO}

Durante o evento, os alunos de ensino médio eram convidados a participar do jogo, e muitos deles se aproximavam de curiosidade, acompanhando o empenho de outros participantes que jogavam individualmente. $\mathrm{O}$ jogo possui quatro perguntas e cada uma possui quatro alternativas sendo apenas uma correta. Em cada apresentação era exibido o prêmio a que se estava concorrendo e, em seguida, a pergunta e as alternativas. Para ilustrar o jogo, segue a imagem de uma pergunta de nível fácil seguida da resposta correta, que é exibida depois que o jogador escolhe sua opção.

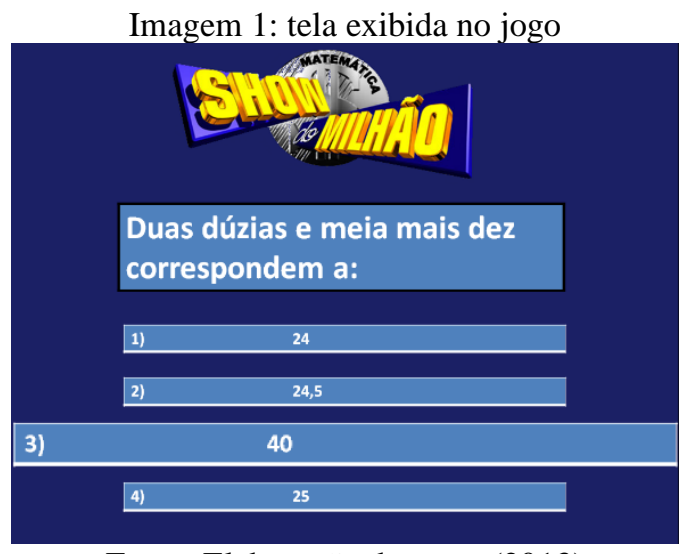

Fonte: Elaboração do autor (2013)

Se o jogador errasse em algum dos três níveis, ele ganhava o prêmio referente ao nível anterior e saia do jogo, dando a oportunidade para outro competidor. Caso contrário, o jogo seguia até a pergunta do terceiro nível e, se acertasse a pergunta, era indagado se queria continuar no jogo e tentar a pergunta final - o grande desafio. Se ele continuasse e acertasse, ganharia o maior prêmio. Se errasse, perderia tudo. Se desistisse do jogo, ganharia o prêmio referente ao terceiro nível.

No desenvolvimento da atividade, pode-se observar que, no início, alguns alunos tinham certo receio ao saber que o jogo só possuía perguntas de Matemática, mas a maioria dos alunos que teve a curiosidade de saber do que se tratava acabou participando da brincadeira. Foi interessante observar também que muitos dos alunos que estavam apenas acompanhando o participante, se sentiam apreensivos e participavam do jogo silenciosamente, pois uma das regras é que se alguém dissesse a resposta para o colega, o mesmo seria desclassificado. A torcida também era grande! Os professores que acompanhavam seus alunos gostaram do jogo pela sua facilidade de modificação e execução. Uma atitude dos alunos que chamou a atenção das licenciandas, surpreendendo-as, foi que, quando erravam a pergunta e o jogo finalizava, eles não saiam até compreenderem porque que sua resposta não estava correta. Com essa experiência, pode-se observar que o jogo e o desafio podem ser explorados no desenvolvimento de conteúdos matemáticos, tornando a disciplina atrativa e mais interativa. 


\section{CONSIDERAÇÕES FINAIS}

A proposta lançada ao grupo de licenciandas e a motivação para elaborar uma atividade dinâmica e atrativa, destacaram ações simples, porém muito importantes, para se trabalhar a matemática, seja em sala de aula, seja em situações nas quais se busca explorar o potencial matemático que cada aluno possui. O jogo é um recurso que pode trazer muitos benefícios, tanto para o professor como para o aluno. Quando o aluno se empenha em resolver um desafio, mesmo quando erra, despertase nele a curiosidade de saber qual é a resposta correta, e consequentemente aprender mais e melhor o conteúdo. O professor e futuros professores podem utilizar esse recurso de modo a contribuir tanto com o ensino que oferecem como com a aprendizagem efetiva de seus alunos. 


\section{REFERÊNCIAS}

BARBOSA, Sandra Lúcia Piola; CARVALHO Túlio Oliveira. Jogos Matemáticos como Metodologia de Ensino Aprendizagem das Operações com Números Inteiros. Disponível em: <http://www.diaadiaeducacao.pr.gov.br/portals/pde/arquivos/1948-8.pdf>. Acesso em: 13 set. 2013.

CARVALHO, Fabrícia Silva et al. Utilização de Jogos Interativos no Ensino a Distância Via Internet. Rio de Janeiro, RJ, 2005. 10 p. Disponível em: <http://www.abed.org.br/congresso2005/por/pdf/040tcc5.pdf>. Acesso em: 13 set. 2013. 